\title{
3D ecosystem modelling in the North Atlantic: relative impacts of physical and biological parameterizations
}

\author{
Svetlana N. Losa ${ }^{\mathrm{a}, \mathrm{b}}$, Alain Vézina ${ }^{\mathrm{c}}$, Daniel Wright ${ }^{\mathrm{c}}$, \\ Youyu Lu ${ }^{\mathrm{c}}$, Keith Thompson ${ }^{\mathrm{a}}$ and Michael Dowd ${ }^{\mathrm{d}}$ \\ ${ }^{a}$ Department of Oceanography, Dalhousie University, Halifax, Nova Scotia, \\ Canada. \\ ${ }^{\mathrm{b}}$ Alfred Wegener Institute for Polar and Marine Research, Bremerhaven, Germany \\ c Bedford Institute of Oceanography, Dartmouth, Nova Scotia, Canada \\ ${ }^{\mathrm{d}}$ Department of Mathematics and Statistic, Dalhousie University, Halifax, Nova \\ Scotia, Canada.
}

\begin{abstract}
A simple ecosystem model is coupled to a 3-dimensional general circulation model for the North Atlantic. The physical model is based on the Los Alamos Parallel Ocean Program (POP) and forced by climatological monthly mean data. Four biological components (phytoplankton, zooplankton, nutrients and detritus) are incorporated into POP as additional tracers with biological sources and sinks. The model solutions, obtained with different physical and biological parameterizations are compared against monthly mean SeaWiFS colour data averaged over the period 1997-2003 and Levitus's climatological nitrate data. A reference model solution, with constant biological model parameters over the whole basin, underestimates both the average chlorophyll level and its regional variability at mid- to high-latitudes. Experiments with a different parameterization of heat and freshwater fluxes, which affects upper ocean mixing, indicate a strong impact of such parameterizations on nutrient supply to the surface layer at high latitudes, but with little impact on simulated chlorophyll. Other experiments where advection of the biological tracers is turned off show basically the same result: strong impact on regional nutrient patterns but a negligible impact on phytoplankton patterns. Only model runs with spatially variable biological parameters, obtained from a previous zero-dimensional ecosystem model calibration on CZCS ocean colour data, could reproduce regional scale patterns in the SeaWiFS imagery. We hypothesize that some of these patterns can be linked to coccolithophore blooms in areas influenced by the N. Atlantic Drift during summer and to effects of temperature on plankton loss rates during spring. Future work should focus on identifying the main factors responsible for these spatial patterns and developing the ecosystem models that can capture them.
\end{abstract}

Preprint submitted to Elsevier Science 22 April 2005 


\section{Introduction}

The opportunity provided by satellites to observe the spatial and temporal (from seasonal to interannual) variability of ocean colour, i.e. of ocean phytoplankton biomass, have inspired much research into 3D coupled physicalbiological modelling at basin and global scales (Dutkiewicz et al., 2001, Carmillet at al., 2001, Gregg 2002, Natvik and Evensen, 2003). While early studies in coupled modelling have mostly focused on quantifying ocean new production (Najjar et al., 1992, Sarmiento et al., 1993, Oschlies and Garçon, 1998, Oschlies, 2001), later studies have tried to interpret (and interpolate) the observed patterns in phytoplankton biomass in order to improve our understanding of the response of marine biota to physical variability, and, ultimately, to develop modelling systems either for long-term prediction of climate feedbacks or for short-term forecasting (Carmillet et al., 2001, Natvik and Evensen, 2003).

The fundamental drivers behind observed annual biological patterns are now well understood. They are related to the seasonal variability in atmospheric conditions which determines the dynamics of the surface ocean mixed layer in which phytoplankton grow. Thus, the better the coupled models can represent the physics, particularly upper ocean physics, the better biogeochemical components can be simulated. A few studies have examined the impact of certain limitations in physical models- such as model resolution, advective and vertical mixing schemes - on simulating ecosystem and biogeochemical dynamics (Oschlies and Garçon, 1998, Oschlies, 2001). However, the coupled models' skill in representing observed phytoplankton dynamics may, to a greater extent, depend on the reliability of the ecosystem part of the coupled models. It is worth noting that there is no consensus on the appropriate level of complexity of the ecosystem model that represents the biological response to physics, or on the appropriate mathematical description of the fluxes between biological compartments. Moreover, the biological models involve a number of a priori poorly known parameters. When developing a coupled physical-biological model at basin or global scales, it is worth keeping in mind that some of the poorly known parameters are not really constant, but may vary in space and time as they depend on different plankton taxonomic composition and on

1 Author for correspondence: Dr. Svetlana Losa, Alfred Wegener Institute for Polar and Marine Research, P.O.Box 120161, 27515 Bremerhaven, Germany, e-mail: sloza@awi-bremerhaven.de 
different responses to environmental conditions.

Calibrating an ensemble of local box ecosystem models between $30^{0} \mathrm{~N}-60^{0} \mathrm{~N}$ latitudes in the North Atlantic, Losa et al. (2004) found notable spatial variations of the biological parameters, that were in qualitative agreement with experimental estimates (Platt et al., 1991, Kyewalyanga et al. 1998). That study implied that, in general, it is difficult to find a single biological model parameter set that can be used successfully over a large domain. Introducing spatial variations in biological parameters allowed Hemmings et al. (2004) to achieve an improvement in simulating, by a grid of simple zero-dimensional models, the observed North Atlantic phytoplankton spatial variations. These authors noted that "the use of different model parameter vectors, with some form of smooth transition over domain boundaries might therefore be the only sensible way of representing some regional variations".

The present study is, to the best of these authors' knowledge, the first attempt to apply the proposition from Hemmings et al. (2004) in a full 3-dimensional model. We have incorporated a simple four-compartment ecosystem model into a three-dimensional general circulation model, based on the Los Alamos Parallel Ocean Program, and then run the coupled physical-biological model, forced by climatological data, with the biological parameter variations estimated by Losa et al. (2004).

Such an experiment is a useful test of the merit of the weak constraint parameter optimization applied by Losa et al. (2004). The parameter estimation was performed using local zero-dimensional ecosystem models constrained by Nimbus-7 surface chlorophyll data averaged over the period from 1979 to 1985. We use these ecological parameter estimates for the 3-dimensional coupled model- assuming that the weak constraint formulation of parameter estimation took into account the errors caused by neglecting the advective transport of the biological components - and compare the coupled model solution against the SeaWiFS chlorophyll estimates averaged over the period from 1997 to 2003.

This experiment also allows us to investigate, in a 3-dimensional application, the impact of biological parameter spatial variability on observed phytoplankton dynamics. Combined with additional sensitivity experiments performed with different model physics, it provides information about the extent to which the physical or biological parts of the coupled model need to be improved.

The paper is organized as follows. In the next section, we give a description of the coupled dynamical models - physical and biological components. The design of the experiments is described in Section 3. Section 4 is devoted to numerical results of the experiments, and Section 5 contains a summary and discussion. 


\section{Dynamical Models}

\subsection{Physical model}

We use the Parallel Ocean Program (POP) to represent physical processes in this study. Details of the POP model are given in Smith et al. (1992) and on the web site http://climate.lanl.gov/Models/POP/index.htm. POP is a fully nonlinear, primitive equation, ocean general circulation model that uses geopotential (z-level) coordinates. Our model domain extends from $30^{\circ} \mathrm{S}$ to $70^{\circ} \mathrm{N}$ and from $100^{\circ} \mathrm{W}$ to $20^{\circ} \mathrm{E}$. The horizontal resolution is $1^{\circ}$ in longitude and $1^{\circ} \cos \phi$ in latitude (where $\phi$ is latitude) so that all grid cells are approximately square. The vertical dimension is discretized into 23 vertical levels, with level thickness increasing from $10 \mathrm{~m}$ at surface to $500 \mathrm{~m}$ near the bottom (cell boundaries are at 10, 20, 35, 55, 75, 100, 135, 185, 260, 360, 510, 710, 985, $1335,1750,2200,2700,3200,3700,4200,4700,5200$ and 5700m).

Sponge layers are included at the northern and southern boundaries to crudely represent the influences of water mass transformations that occur outside of the model domain, thus influencing the properties at these boundaries. Within these layers, the temperature and salinity are strongly restored towards monthly climatological values; the restoring time is set at 2 days in the cells adjacent to the boundaries and the inverse of the restoring time decreases linearly to zero over the 5 degree bands extending into the model domain. A similar sponge region is included at the Strait of Gibraltar. In this case, the restoring time is set at 2 days in the strait and the inverse of this time scale decreases linearly to zero at a distance of $3^{\circ}$ from the strait.

The K-profile parameterization (Large et al., 1994) is used to parameterize unresolved vertical mixing processes. The effects of meso-scale eddies are parameterized by a variation of the scheme proposed by Gent and McWilliams (1990) in which the eddy-induced advection velocity is implemented in the momentum rather than in the tracer equations (see section 4 of Gent et al., 1995 for a discussion of this approach). The spatially varying mixing parameterization proposed by Visbeck et al. (1997) is used with the horizontal length scale chosen as 3.5 times the local internal Rossby radius and the resulting transfer coefficient bounded between 300 and $2000 \mathrm{~m}^{2} / \mathrm{s}$. Isopycnal mixing with a constant mixing coefficient of $1000 \mathrm{~m}^{2} / \mathrm{s}$ is also included. Biharmonic momentum mixing is used with a mixing coefficient that varies as the fourth power of the horizontal grid spacing with a maximum value at the equator of $-2 \times 10^{22} \mathrm{~cm}^{4} / \mathrm{s}$. A weak biharmonic mixing term is also applied to the tracers but the coefficient is $1 / 16$ th of that used in the momentum equations and the effect on the scales of interest here is small. 
The model is initialized with zero flow and the temperature and salinity specified according to the January values of the climatology developed by Dr. Yashayaev at the Bedford Institute of Oceanography (personal communication, Yashayaev, 2004). All of the forcing fields are based on monthly climatology of surface fluxes taken from da Silva et al. (1994) and linearly interpolated to the current time step. The surface temperature boundary condition is the net heat flux plus a restoring to surface temperature. The restoring time varies both spatially and temporally according to Barnier et al. (1995). The surface salinity boundary condition is the virtual salt flux computed from the rate of evaporation minus precipitation, plus a restoring towards the Yashayaev's surface salinity climatology on a time scale of 30 days.

\subsection{Ecosystem model}

For the biological component of the model, we adopted the ecosystem model developed by Popova (1995). This model, part of the NPZD family of models (for Phytoplankton, Zooplankton, Nutrients and Detritus), represents a good initial compromise between complexity (number of compartments and adjustable parameters) and representation of the planktonic ecosystem. Also, the data available at basin scales to test the model - ocean colour and nutrients - pose limits on the complexity of the biological model that can be tested. The model has been previously tested, with a single parameter set, for a few locations in the North Atlantic (Popova, 1995). A detailed description of the model can be found in the appendix.

Briefly, the ecosystem model is a reduced version of the FDM model (Fasham et al. 1993) and describes the dynamics of state variables $\mathrm{P}, \mathrm{Z}, \mathrm{N}$ and $\mathrm{D}$ as four coupled differential equations (see Appendix). The model tracks nitrogen flows through these compartments, as is the common practice for areas like the North Atlantic that are nitrogen-limited. The major processes considered by the ecosystem model (Figure 1) are primary production by phytoplankton $P P$, controlled mainly by nutrient $N$ and light availability $I$ (with temperature influencing the maximum growth rate); phytoplankton losses that include natural mortality and other processes such as aggregation into larger particles $D_{P}$ and zooplankton grazing $G_{P}$; nutrients input by means of upwelling and turbulent mixing; detritus sinking and remineralization due to detritus breakdown $D_{D}$ and transformation of a fraction of the total zooplankton losses $D_{Z}$ into dissolved inorganic nitrogen.

The P, Z, N, D biological components were incorporated in the POP code as four additional tracers, similar to $\mathrm{T}$ and $\mathrm{S}$. Biogeochemical sources and sinks (differential equations in Appendix) were added to these new tracer equations. There are no feedbacks from the evolution of the biological tracers 
on the radiative heat fluxes in the water column. All boundary conditions were treated in the same way as for $\mathrm{T}$ and $\mathrm{S}$, except for the sea surface boundary where all biological fluxes are assumed to be equal to 0 . Thus the southern and northern boundaries are closed with sponge layers where the biological tracers relax to their climatologies:

- Climatological seasonal mean nitrate, derived from the World Ocean Database (1998).

- Climatological monthly mean surface chlorophyll estimates, obtained by averaging SeaWiFS data over the period 1997-2003. To convert the chlorophyll concentration, which is not a state variable in the model, to the phytoplankton biomass, we used the empirical $C h l: C$ relationship proposed by Cloern et al (1995) (Chl:C=a+be $e^{c T_{w}} e^{-d I} \frac{N}{k_{1}+N}$, where $a, b, c$, and $d$ are some constants) and an average value for the $C: N$ ratio $(=6.625 \mathrm{~mol} / \mathrm{mol})$. Following Natvik and Evensen (2003) we assume phytoplankton concentration to decrease exponentially with depth $P(k)=P(1) e^{-\frac{(z(k)-z(1))^{2}}{z_{c h}}}(z(k)$, $k=1,2, . ., 23)$, with $z_{c h}=100 m$.

- Comparable climatologies do not exist for Z and D. Zooplankton and detritus in the sponge layer were chosen to be $Z=0.02 \mathrm{mmol} N \mathrm{~m}^{-3}$ and $D=0.1 \mathrm{mmol} \mathrm{N} \mathrm{m}^{-3}$ at the surface and then, similar to P, the concentrations decrease exponentially with depth over the characteristic scale depth of $100 \mathrm{~m}$.

For all the experiments described here, the physical model was run for 20 model years, until an almost stationary solution for the physics was achieved, and then the coupled model was run for an additional 5-7 years to obtain a quasi-steady state for the biology. The January climatology is used to initialize the model biology.

\subsubsection{Model parameters}

As for any ecosystem model Popova's (1995) model possesses a number of adjustable biological parameters (Table 1). Sensitivity analyses for the ecosystem model (Popova 1995, 1997) have revealed the biological parameters to which the model is more sensitive. The most sensitive parameters include: phytoplankton growth rate constant $V_{p}^{*}$, the initial slope of the P-I curve $\alpha$, the phytoplankton maximum specific mortality rate $\mu_{1}$, the zooplankton maximum loss rate $\mu_{2}$, the zooplankton maximum ingestion $g$, and the zooplankton ingestion half-saturation constant $k_{3}$.

Losa et al. (2004) optimized these parameters, by means of a weak constraint variational technique, for the very same ecosystem model, in each cell of a $5 \times 5^{\circ}$ grid covering the North Atlantic from $30^{\circ} \mathrm{N}$ to $60^{\circ} \mathrm{N}$. It is worth emphasizing that the model was constrained at that time by the surface chlorophyll "a" 
data obtained from the coastal zone color scanner (CZCS) and averaged over the period 1979 to 1985 . In the 3D experiments presented here, the model results are compared to an independent data set from SeaWIFs (averaged over 1997-2003) with no further tuning of the parameters. Further, the biological parameters estimated by Losa et al. (2004) vary in space but not in time. The seasonal variations discussed below are driven by the seasonal forcing applied to the model primarily through the surface fluxes of heat and salt.

\section{Experiment design}

The results presented and discussed in this paper are based on four experiments, summarized in Table 2. The first two experiments contrast the use of constant versus spatially variable parameters using the reference version of the physics implemented in the North Atlantic POP model (section 2.1):

- Experiment 1 - biological parameters are treated as constant and equal to values of Popova (1995), summarized in Table 1;

- Experiment 2 - the biological parameters $V_{p}, \alpha, g, k_{3}, \mu_{1}$ and $\mu_{2}$ are assumed to be spatially variable. The biological parameter fields were taken from Losa et al. (2004) and then linearly interpolated and extrapolated from the domain of $30^{\circ} N-60^{\circ} \mathrm{N}$, considered in Losa et al. (2004), onto the current coupled model grid (Figure 2). Extrapolation was done in such a way that, outside of the $30^{\circ} \mathrm{N}-60^{\circ} \mathrm{N}$ domain, the biological parameters relax to Popova's (1995) values over an horizontal distance of $20^{\circ}$.

To assess the relative impact of biological model and physics parameterizations on the simulated chlorophyll and nitrate fields, we ran two other experiments with modifications to the physical part of the coupled model. We examined the impact of running both versions of the biological model (i.e. constant vs variable parameters) with a test version of the surface physics (experiments 3 and 4 in Table 2). In that test version, the surface heat and fresh water fluxes are parameterized as specified fluxes plus a simple restoring term on a time scale of 60 days (instead of the restoring term being dependent on the observations as in the Barnier et al. (1995) scheme). Furthermore, in the test version, the mean, annual and semi-annual components were strongly restored in the surface layer for both $\mathrm{T}$ and $\mathrm{S}$ whereas in the reference version, only the mean and annual cycles are strongly restored. There were other differences between both versions of the physics, but additional sensitivity experiments (not shown) indicated that these changes in surface layer physics had the most impact on biology simulations. It is worth noting that the changes in the physical model from the old (experiments 3 and 4 ) to the new reference version (experiments 1 and 2) were initially implemented to improve the physical part of the simulations (temperature and salinity fields, mixed layer dynamics) and 
did not consider the impact on biological simulations.

\section{Results}

\subsection{Base simulation}

Figures 3 and 4 depict seasonal means of the North Atlantic surface chlorophyll "a" (Chl) and dissolved inorganic nitrogen (DIN) concentrations, simulated by the reference experiment (Experiment 1). The simulations reproduce high Chl and DIN concentrations and a strong seasonal cycle at the mid- to high latitudes of the North Atlantic, while concentrations remain low and relatively invariant year-round in the interior of the oligotrophic Subtropical Gyre and at lower latitudes of the North Atlantic, except for the regions of elevated Chl - the upwelling regions off West Africa and along the equator. The model reproduces a "rolling green carpet", where relatively high Chl values appear first in the Subtropical Gyre in winter and then intensify and move north through the spring and summer, before falling and retreating to the Subtropical Gyre during autumn (Fig. 3). The simulated surface DIN concentrations show the corresponding pattern (Fig. 4), with levels rising from South to North, concentrations falling during the spring and summer, and the $2 \mathrm{mmol} \mathrm{N} \mathrm{m}^{-3}$ isoline retreating northward during the summer.

These large scale spatial and seasonal patterns of the simulated Chl and DIN concentrations qualitatively agree with observed North Atlantic ecosystem seasonal dynamics (Figure 5). For each model grid cell, we calculated the correlation between monthly means of simulated Chl concentrations and SeaWiFS colour data averaged over the period of 1997-2003 (not shown). The correlations were positive for most of the basin, except for a small area of the Subtropical Gyre and some regions in the Equatorial Atlantic, where the seasonal cycles of both phytoplankton and dissolved inorganic nitrogen are probably too weak and the interpretation of any correlation coefficient is doubtful. Similar to the coupled models used in previous studies (Sarmiento et al, 1993, Oschlies and Garçon, 2000, Oschlies, 2001, Gregg, 2002, Gregg et al., 2003), this model qualitatively captures essential features of the ocean phytoplankton dynamics, except for the coastal and shelf regions that are beyond the scope of coarse resolution models.

Our simulation has, however, revealed difficulties in reproducing the intensity and variability of the chlorophyll field. These limitations are illustrated by comparing Figure 3 with Figure 5. The simulated Chl concentrations to the north of $35^{0} \mathrm{~N}$ and in upwelling regions off western $\mathrm{N}$. Africa are systematically lower than those derived from the satellite data, while the surface Chl is over- 
estimated, in comparison with the observations, along the equator and in the Subtropical Gyre during winter and spring. It is worth noting that similar discrepancies have been found in other 3D basin scale coupled physical-biological modelling studies (e.g. Oschlies and Garçon, 2000, Oschlies, 2001, Gregg et al. 2003), using coarse (Gregg et al. 2002) and even much finer resolution models (Oschlies and Garçon, 2000, Oschlies, 2001) . These authors also mentioned difficulties in reproducing ecosystem dynamics in oligotrophic regions, such as the Subtropical Gyre. Also note that the simulation does not capture the regional scale patches observed at mid- and high latitudes during all seasons but particularly during summer.

\subsection{Simulation with spatially variable biological model parameters}

The seasonal means of surface chlorophyll "a" simulated with the variable biological parameters, as determined from the results of Losa et al. (2004), are shown in Figure 6. Comparing Figure 5 with Figure 6 shows noticeable improvements in the spatial and temporal variations in Chl obtained with variable parameters. For winter, the model still underestimates Chl in the subpolar gyres but better reproduces higher Chl regions over the Grand Banks and in the northern North Sea (note that due to sparse data, the SeaWiFS Chl is probably an overestimate for this period). For spring, introducing spatially variable biological parameters leads to marked improvements in simulating Chl concentrations in the NW Atlantic, around the Labrador Sea, and in the northern North Sea, with only minor impacts on the NE Atlantic. For summer, the variable parameter simulation produces regional scale patches over the Grand Banks, in the northern extension of the subtropical gyre southwest of Iceland (approx. $50^{\circ} \mathrm{N}$ and $45^{\circ} \mathrm{W}$ ), and over the Rockall Trough and the Norwegian Sea. These simulated spatial structures present a better match to the regional structure observed in the SeaWIFS imagery, except for the regions south of Iceland where the model consistently underestimates Chl levels. Comparable improvements in the reproduction of spatial structure can be seen in the Autumn simulation results. Most of the improvements are concentrated north of $35^{0} N$. This is to be expected since Losa et al. (2004) obtained their parameter estimates for the domain between $30^{\circ} \mathrm{N}$ and $60^{\circ} \mathrm{N}$.

The Chl simulation from Experiment 2 clearly reproduces the data much better than the simulation from Experiment 1. Some discrepancies between the Experiment 2 model chlorophyll and the data, however, still remain:

1 Simulated phytoplankton abundance is low in the regions just south of Iceland, as mentioned above. The reference physics lead to deep mixed layers near Iceland which are not observed in the upper mixed layer (UML) climatologies. The low simulated $\mathrm{Chl}$ in that area probably results from the neg- 
ative impact of exceedingly deep mixed layers on production (Dutkiewicz, 2001) and are related to misrepresentations of mixing by the physical model.

2 The high chlorophyll "spot" in the northern extension of the Subtropical Gyre is more concentrated in the model case than it is in the data. This may be due to the lack of mesoscale processes, that are not resolved by the model. It is also worth keeping in mind potential problems with the interpolation of the parameters from zero-dimensional models to the twodimensional pattern.

Nevertheless, it appears that the observed pattern of the phytoplankton in the Subpolar North Atlantic is strongly influenced by spatuial variations in ecological processes. This reflects the fact that planktonic ecosystems, composed of different species assemblages, respond differently to the physical forcing imposed by the numerical model.

\subsection{Sensitivity experiments}

Figures 7 and 8 depict grid cell differences in the annual means of surface chlorophyll and nitrogen concentrations, respectively, between pairs of experiments described in the previous section (see Table 2). For chlorophyll, comparing these differences with the differences between observed chlorophyll from SeaWiFS (Fig. 5) and simulations can be used to assess whether different experiments improve or worsen the match to observed chlorophyll. Only annual mean differences are presented as we found that spatial patterns in the differences are roughly consistent across seasons (see Figs 3-6).

The major impact on Chl a simulations of using different parameterizations of the surface heat and fresh water fluxes is in the region from $40^{\circ} \mathrm{N}$ to the south (Fig. 7a). The change to the reference version of the physics, while keeping biological parameters constant over the basin (Experiments 1 and 3), slightly increased simulated $\mathrm{Chl}$ in the subtropical gyre (order $0.1 \mathrm{mg} \mathrm{Chl}$ $\mathrm{m}^{-3}$ ), while reducing simulated $\mathrm{Chl}$ by similar amounts in convective regions in the Labrador and Irminger Seas, in the Norwegian Sea and over the Rockall plateau west of the United Kingdom. Given that the reference run (Experiment 1) overestimates $\mathrm{Chl}$ in the subtropical region and underestimates Chl at higher latitudes, the change to a new physics version actually made the fit to SeaWiFS data slightly worse. In contrast to Chl simulations, simulated surface DIN is very sensitive to the changes in the surface flux parameterizations at the mid- to high latitudes of the North Atlantic (Figure 8a). The increase in nitrate concentration obtained by switching to the reference version of the physics reaches $2-5 \mathrm{mmol} N \mathrm{~m}^{-3}$ in the Labrador and Irminger Seas and in the N. Atlantic drift. Comparison with the nitrate climatology (not shown) indicates that the switch to the reference version of the physics improved the 
match between simulated and observed surface nutrients.

By comparing Figure $7 \mathrm{a}$ with $7 \mathrm{~b}$, one can see that the change from constant to spatially variable parameters had a much stronger impact on simulated Chl fields from $40^{\circ} \mathrm{N}$ than the change in physical parameterizations. The annual mean differences in Fig. 7b reflect well the seasonal differences discussed above. In contrast, the change from constant to spatially variable biological parameters had a relatively small impact on the DIN simulations (Figure 8b). The change to spatially variable parameters does increase DIN concentrations in the Subpolar Gyre complex and the northern extension of the Subtropical Gyre and decreases DIN levels in the Gulf Stream. However, these changes are small relative to those induced by changing the physics.

The same spatial pattern of Chl and DIN sensitivity to physics is seen when the spatially variable biological parameters are run with the reference and test versions of surface physics (Figs. 7c and 8c). The use of spatially variable parameters, however, does make the simulated Chl and DIN fields more sensitive to the change in physics. Changing from constant to variable parameters with the test version of the physics (Figs. $7 \mathrm{~d}$ and $8 \mathrm{~d}$ ) also leads to similar results as with the reference version (Figs. $7 \mathrm{~b}$ and $8 \mathrm{~b}$ ), except that the sensitivity to the change in the biological model is stronger with the test version of the physics.

\section{Summary and Discussion}

A NPZD ecosystem model with a single parameter set, coupled with an ocean general circulation model (POP), can simulate the major features of the seasonal cycle of biological production at basin scales in the North Atlantic. However, as also noted in previous coupled modelling studies, this approach results in systematic regional scale biases in reproducing surface chlorophyll and underestimates the spatial variability of the chlorophyll field at mid- and highlatitudes. Experiments with different versions of the surface physics indicate that changing the physics alone was not able to correct for these deficiencies. The change in air-sea parameterizations in POP led to dramatic changes in the spatial and seasonal distribution of vertical mixing and surface nutrients, mainly by substantially increasing nutrient supply in high latitude convective regions and in the western part of the N. Atlantic Drift. Nevertheless, these changes in nutrients had small impacts on simulated chlorophyll, probably because these are regions where light limitation plays a major role in regulating phytoplankton production (Dutkiewicz et al. 2001). In fact, the change to improved physics actually made the correspondence between simulated and observed (SeaWiFS) chlorophyll slightly worse, reinforcing the biases in the coupled model simulations towards underestimating Chl at high latitudes and overestimating Chl at low latitudes. 
Additional experiments not presented here examined the impact of advection on the simulated $\mathrm{Chl}$ and nutrient patterns. In these experiments, the advective terms were maintained for $\mathrm{T}$ and $\mathrm{S}$ for the full model integration, while advection of the biogeochemical tracers was turned off during the integration of the biological model. While such an experiment may be valid only for short-term simulations (1-10 years), these simulations indicated that biological tracer advection plays a similar role to vertical mixing in controlling simulated Chl patterns. Turning off advection of ecosystem components has major impacts on simulated surface nutrients, particularly in the intergyre zone (between the subtropical and subpolar gyres) and in the subpolar gyre complex, but the impacts on simulated Chl are relatively small. This is especially true for the reference version of the coupled model with the improved surface physics. Removing biological tracer advection revealed a major role for transport from the intergyre zone and around the subpolar gyre in maintaining high-latitude surface nutrient concentrations. Yet, the impact on simulated Chl was negligible. Dutkiewicz et al. (2001) suggested that interannual variability in phytoplankton in the intergyre zone may be strongly affected by advective processes. Our simulation experiments do not indicate a strong sensitivity of phytoplankton to advection in this area and raise more questions about the regulation of biological production in that complex regime.

Therefore, similar to other studies, which used higher resolution models (Oschlies and Garçon, 1998, Oschlies, 2001) with even more sophisticated advection schemes, we find that the simulated chlorophyll "a" concentrations at mid- to high-latitudes remain low, in comparison with the observed data, in all the experiments with different physics. This points to problems with the biological part of the coupled model. Before introducing more complexity in the ecosystem model, however, we consider the effect of using the spatially variable biological parameters already obtained by Losa et al. (2004) in an effort to better identify a potential source for the spatial variability unresolved by the current model.

First, we found that the spatially variable parameters do help in reproducing the regional scale variability in SeaWiFS data north of $40^{\circ} \mathrm{N}$, despite the fact that Losa et al. (2004) based their parameter estimates on the independent, and 20-year old, CZCS data. This suggests a long-term stability in some major features of the N. Atlantic plankton ecosystems and their relationship to physics.

Second, one possible explanation for some the regional scale variability is the seasonal development of large scale coccolithophorid (represented by Emiliania huxlei) blooms. These blooms have been clearly detected by remote sensing (Holligan et al., 1993, Brown and Yoder, 1994, Brown, 1999, Iglesias-Rodríguez et al., 2002) and are observed consistently during summer in the Norwegian Sea, in the Rockall plateau/trough area, and in the northern extension of 
the Subtropical Gyre southwest of Iceland. Iglesias-Rodríguez et al.(2002) depicted the spatial distribution of Emiliania huxlei in the N. Atlantic based on reflectance in SeaWiFS imagery. Their distribution reveals regional patterns very similar to those discussed in this paper for summer.

While diatoms are the best known bloom-forming phytoplankton prevailing over the ocean, Emiliania huxlei are responsible for recurrent summer blooms associated with certain environmental conditions, such as strong thermal stratification, temperature between $5^{\circ} \mathrm{C}$ and $15^{\circ} \mathrm{C}$, high solar radiation and low and declining nutrient concentrations (Iglesias-Rodriguez et al, 2002, Paasche, 2002). Indeed, under these conditions Emiliania huxlei has an advantage over the other phytoplankton taxa due to its physiological characteristics: it has a high affinity for DIN and, unusually in comparison with other phytoplankton species, it is immune to photoinhibition even at very high solar irradiance (Tyrrell and Taylor, 1996). Photosynthesis in Emiliania huxlei is associated with a low value of the initial slope of the $P-I$ curve, $\alpha$ (Nanninga and Tyrrell, 1996). Therefore, this species does not compete at low irradiance, but grows at a rather high rate at high light intensities.

Moreover, there is some evidence that the coccolithophorid blooms can be supported by decreasing zooplankton grazing pressure. Huskin et al (2000), in laboratory experiments, found low ingestion in copepods fed with Emiliania huxlei. In the experiments performed by Nejstgaard et al. (1997), microzooplankton grazing rates upon Emiliania huxlei were shown to be very low, leading the authors to conclude that coccolithophorid species did not support microzooplankton growth - in contrast to grazing controlled diatoms and flagellates - "but escaped grazing control and was able to produce nearly monospecific blooms".

The spatial structure of light utilization and grazing parameters optimized by Losa et al. (2004) (see Figure 2) can be compared to the observed regional scale Chl patches captured by the coupled model with the spatially variable biological parameters. The optimized $\alpha$ values decrease from south to north in the N. Atlantic, and reach their lowest values in the Grand Banks and Subtropical extension. At the same time, the optimized maximum phytoplankton growth rates rise from southwest to northeast in the N. Atlantic, roughly corresponding with the distribution of the regional Chl patches. The optimized grazing half-saturation constants reach high values in the Subtropical extension and Rockall plateau/Norwegian Sea. Thus, the coupled model with variable biological parameters has simulated the regional scale patches by decreasing the light efficiency of phytoplankton, increasing their maximum growth rate and decreasing the loss rates due to zooplankton grazing (at low prey concentrations). These parameter adjustments are consistent with what is known of Emiliania huxlei ecophysiology. 
Moreover, the regional patches are associated with the N. Atlantic Drift that brings warm, stratified and nutrient poor waters to the NE Atlantic. These are conditions that will favour coccolithophorid blooms. These are also conditions that under standard parameter sets generate low production and low biomass accumulation in NPZD models. Only adjustments of the parameters to reflect ecological adaptations to these conditions can reproduce the observed variability in surface Chl fields.

Another possible explanation for at least some of the regional scale structure is dependence of loss rates (mortality, grazing) on temperature. Our NPZD model, based on previous models commonly used in basin scale simulations, assumes only phytoplankton growth rate to be temperature-dependent. We performed additional simulations (not shown) to investigate the impact of keeping the biological parameters constant over the basin but making phytoplankton and zooplankton loss rates (e.g. mortality, grazing) temperaturedependent as well, following the same temperature-dependence assumed for growth rates. We found an improvement in model-data agreement for late winter and spring in areas of the NW and NE Atlantic (Grand Banks, northern N. Sea). Therefore, improving the way models represent temperature effects on ecological rates may also help capturing some of the regional scale variability.

The fact that the biological parameters, obtained by means of calibrating (tuning) an ensemble of local UML ecosystem models, have worked well for the 3-dimensional coupled physical-biological model, reveals the advantages of the weak constraint parameter optimization procedure used by Losa et al. (2004), in particular, the implemented approach for weighting terms in the cost function (Kivman et al., 2001). To our knowledge, this is the first time parameters obtained from running and calibrating multiple zero-dimensional ecosystem models have been implemented successfully in a 3D model. Given the difficulty and computing costs involved in estimating biological parameters in full 3D simulations, this indirect method remains an attractive alternative.

On the other hand, this work shows, once again, that the biological response to variability in the physics is local and species-dependent (Longhurst 1998). Developing parameterizations of this variable response remains a challenge. As we could ascertain from the coupled model sensitivity experiments, the model's skill in representing observed chlorophyll depends crucially on such parameterizations. For accurate simulations of the annual phytoplankton cycle or of the interannual variability in biological production, at the mid- to high latitudes of the North Atlantic, the ecosystem model will need at least as much attention - if not more - as the physical model. It is worth emphasizing that we do not imply that a correct representation of the physics is not important. It appears, however, that the issues discussed here will not be resolved by increasing the resolution of the physical model, but only by increasing the ecological resolution of the ecosystem model. Including multiple (at least 
two) phytoplankton taxa and, probably zooplankton taxa as well, might be suggested as an initial approach to improve the ecosystem model. Our results suggest that incorporating a taxa representative of Emiliana huxleyi is a priority for the N. Atlantic. A few attempts to include multiple taxa in 3D models have already been made (Gregg et al., 2003). However, one has to be reasonably confident in the parameterizations of the ecological or physiological differences among plankton taxa; otherwise, we are just compounding uncertainties in a more complex ecosystem model. Moreover, it is worth keeping in mind that the representations of plankton physiological dependences on environmental conditions still do not reflect known processes such as acclimation of different species to temperature changes (Moisan et al. 2002). Nevertheless, at the present stage of our knowledge (or dare we say, our established mathematical descriptions) of the processes regulating ecosystem dynamics and biogeochemical cycling in the ocean, a correct formulation of the data assimilation (parameter estimation) problem in ecosystem modelling remains a powerful tool to extract and combine the information from two different sources - the model and the data - in order to improve our understanding of both sources and, therefore, of reality itself.

\section{Acknowledgments}

The work has been supported through the Strategic Science Fund of the Department of Fisheries and Oceans, Government of Canada. NASA/ GSFC/ DAAC provided the SeaWiFS data, used for initializating and validating the model. The authors are grateful to Dr. Claudia Sprengel and Prof. Dr. Ulrich Bathmann for discussions of coccolithophore physiology and zooplankton grazing. Comments and support by the editors and anonymous reviewers were very helpful.

\section{A Biological Model Equations}

The ecosystem $\left(c_{i}, i=P, Z, D, N\right)$ dynamics is described by the following equations:

$$
\frac{\partial}{\partial t} c_{i}-\nabla\left(K_{h} \nabla c_{i}\right)+\nabla\left(V c_{i}\right)-\frac{\partial}{\partial z}\left(K_{v} \frac{\partial c_{i}}{\partial z}\right)=B_{i}
$$

where $\nabla$ is the two-dimensional gradient operator, $K_{h}$ and $K_{v}$ are the horizontal and vertical diffusivity coefficients, $V$ is the two-dimensional velocity vector, $B_{i}$ are biological sources and sinks.

Following Popova (1995), the biological sources and sinks $B_{i}$ are expressed as 


$$
\begin{array}{r}
B_{P}=P P-G_{P}-D_{P} \\
B_{Z}=\beta_{1} G_{P}+\beta_{2} G_{D}-D_{Z} \\
B_{D}=\left(1-\beta_{1}\right) G_{P}-\beta_{2} G_{D}-D_{D}+D_{P} \\
B_{N}=-P P+m D_{Z}+D_{D}
\end{array}
$$

where $P P=J Q P$ is the daily mean phytoplankton growth rate, $J$ is the light-limited growth rate, $Q$ is a non-dimensional limiting factor, $G_{P}$ and $G_{D}$ are grazing rates of the zooplankton on the phytoplankton and on the detritus respectively, $\beta_{1}$ and $\beta_{2}$ are equivalent assimilation efficiencies, $D_{P}$ is the rate of phytoplankton losses, including natural mortality and other processes such as aggregation into larger particles, $D_{Z}$ is the rate of zooplankton losses due to excretion, natural mortality and grazing of higher order predators, $D_{D}$ is the rate of detritus breakdown, and $m$ is a fraction of the total zooplankton losses transformed into dissolved inorganic nitrogen.

Following Fasham (1993), $J, Q, D_{P}, D_{Z}$ and $D_{D}$ are given as

$$
\begin{array}{r}
J=\frac{1}{h} \int_{0}^{h} F\left[I_{0}(t) \exp \left\{-\left(k_{w}+k_{c} P\right) z\right\}\right] d z, \quad Q=\frac{N}{k_{1}+N}, \\
D_{P}=\frac{\mu_{1} P^{2}}{k_{5}+P}, \quad D_{Z}=\frac{\mu_{2} Z^{2}}{k_{6}+Z}, \quad D_{D}=\mu_{4} D,
\end{array}
$$

where $F(I)=V_{p} \alpha I /\left(V_{p}^{2}+\alpha^{2} I^{2}\right)^{1 / 2}, V_{p}=V_{p}^{*} 1.066^{T_{w}}$ is the maximum phytoplankton growth rate, $\alpha$ is the initial slope of the P-I curve, $I=I(z, t)$ is the photosynthetically available radiation at depth $z, I_{0}=I(0, t)$ is assumed to be proportional to the absorbed total irradiance at the sea surface, and the ratio $\lambda_{p}$ of $I_{0}$ to the irradiance being prescribed; $k_{w}$ is the light attenuation coefficient due to water, $k_{c}$ is the phytoplankton self-shading parameter, $T_{w}$ is the water temperature, $z$ is the vertical coordinate, $k_{1}, k_{5}, k_{6}, \mu_{1}, \mu_{2}, \mu_{3}$ and $V_{p}^{*}$ are model parameters. The zooplankton grazing rates $G_{P}$ and $G_{D}$ are described by the following expressions:

$$
G_{P}=g Z \frac{r_{1} P^{2}}{k_{3}+r_{1} P^{2}+r_{2} D^{2}}, \quad G_{D}=g Z \frac{r_{2} D^{2}}{k_{3}+r_{1} P^{2}+r_{2} D^{2}}
$$

which are multi-prey generalizations of the Holling type III function. Here $r_{1}$ and $r_{2}$ are the weighted preferences for phytoplankton and detritus, $g$ and $k_{3}$ are the maximum specific grazing rate and the half-saturation constant for grazing. 


\section{References}

[1] Barnier, B., L. Siefridt, and P. Marchesiello, 1995. Thermal forcing for a global ocean circulation model using a three-year climatology of ECMWF analyses. J.Mar. Syst., 6, 363-380.

[2] Brown, C.W., 1999. Spatial and temporal variability of Emiliania huxleyi blooms in the SeaWiFS imagery. Eos Trans. AGU, 80(49) Suppl., 153.

[3] Brown, C.W., and J.A. Yoder, 1994. Coccolithophorid blooms in the global ocean. J. Geophys. Res., 99, 7467-7482.

[4] Carmillet, V., Brankart, J.-M., Brasseur, P., Drange, H., and Evensen, G., 2001. A singular evolutive extended Kalman filter to assimilate ocean color data in a coupled physical-biochemical model of the North Atlantic. Ocean Modelling 3, 167-192.

[5] Cloern, J.E., Grenz, C. and Vidergar-Lucas, L., 1995. An empirical model of the phytoplankton chlorophyll: carbon ratio - the conversion factor between productivity and growth rate. Limnol. Oceanogr. 40, 1313-1321.

[6] Dutkiewicz, S., Follows, M. and Gregg, W.W., 2001. Interannual variability of phytoplankton abundances in the North Atlantic. Deep-Sea Research II, 48, 2323-2344.

[7] Fasham, M.J.R., 1993. Modelling the marine biota. The global carbon cycle. edited by M.Heimann, Springer-Verlag, New York, 547-504.

[8] Garçon, V.C., Oschlies A., Doney, S. C., McGillicuddy, D., Waniek, J., 2001. The role of mesoscale variability on plankton dynamics in the North Atlantic. Deep-Sea Research II, 48, 2199-2226.

[9] Gent, P.R., J. Willebrand, T.J. McDougall and J.C. McWilliams, 1995. Parameterizing eddy-induced tracer transports in ocean circulation models. J. Phys. Oceanogr., 25, 463-474.

[10] Gregg, W. W., 2002, Tracking the SeaWiFS record with a coupled physical/biogeochemical/radiative model of the global oceans. Deep-Sea Research II, 4, 81-105.

[11] Gregg, W. W., P. Ginoux, P. S. Schopf, N. W. Casey, 2003. Phytoplankton and iron:validation of a global three-demensional ocean biogeochemical model. Deep-Sea Research, 50, 3143-3169.

[12] Hemmings, J.C.P., Srokosz, M.A., Challenor, P. and Fasham, M.J.R., 2004. Split-domain calibration of an ecosystem model using satellite ocean colour data. J. Mar. Sys., 50,141-179.

[13] Holligan, P.M., Fernádez, E., Aiken, J., Balch, W.M., Boyd, P., Burkill, P.H., Finch, M., Groom, S.B., Malin, G., Muller, K., Trees, C.C., Turner, S.M., van der Wal, P., 1993. A biogeochemical study of the coccolithophorid Emiliania huxleyi, in the North Atlantic. Global Biogeochem. Cycles, 7, 879-900.

[14] Huskin, I., Anadon, R., /'Anadon-Marqu/'es, F., Harris, R.P., 2000. Ingestion, faecal pellet and egg production rates of Calanus helgolandicus feeding coccoliphophorid versus non-coccolithophorid diets. Jornal of Experimental Marine Biology and Ecology, 248, 239-254. 
[15] Iglesias-Rodríguez, M. D., Brown, C. W., Doney, S. C., Kleypas, J., Kolber, D., Kolber, Z., Hayes, P. K., Falkowski, P. G., 2002. Representing key phytoplankton functional groups in ocen carbon cycle models: Coccolithophorids. Global Biogeochemical Cycles, 16(4), doi: 10.1029/2001GB001454.

[16] Kivman, G.A., Kurapov, A.L., Guessen, A.V., 2001. An entropy approach to tuning weights and smoothing in the generalized inversion. J. Atmos. Ocean. Technol. 18, 266-276.

[17] Kyewalyanga, M. N., Platt, T., Sathyendranath, S., Lutz, V. A., and Stuart, V., 1998. Seasonal variations in physiological parameters of phytoplankton across the North Atlantic. J. Plankton Res., 20, 17-42.

[18] Large, W.G., McWilliams, J.C.and Doney, S.C., 1994. Oceanic vertical mixing: A review and a model with non-local baundary layer parameterization. Reviews of Geophysics, 32(4), 363-403.

[19] Levitus, S. and Boyer, T.P., 1994. World Ocean Atlas. Temperature. Washington, D.C.: NOAA, 4, 117 p.

[20] Losa, S.N, Kivman, G.A., and Ryabchenko, V.A., 2004. Weak constraint parameter estimation for a simple ocean ecosystem model: what can we learn about the model and data? J. Mar. Sys., 45, 1-20.

[21] Moisan, J.R., Moisan, T.A. and Abbott, M.R.. 2002. Modelling the effect of temperature on the maximum growth rates of phytoplankton populations. Ecol. Model., 153, 197-215.

[22] Najjar, R.G., Sarmiento, J.L. and Toggweiler, J.R., 1992. Downward transport and fate of organic matter in the ocean: Simulation with a general circulation model. Global Biogeochemical Cycles, 6, 45-76.

[23] Nanninga, H. J., Tyrrell, T., 1996. Importance of light for the formation of algal blooms of Emiliania huxleji. Mar. Ecol. Progr. Ser., 136, 195-203.

[24] Natvik, L.-J. and Evensen, G., 2003. Assimilation of ocean colour data into a biochemical model of the North Atlantic. Part 1. Data assimilation experiments. J. Mar. Sys., 40-41, 127-153.

[25] Nejstgaard, J. C., Gismervik, I., Solberg, P., 1997. Feeding and reproduction by Calanus finmarchicus, and microzooplankton grazing during mesocosm blloms of diatoms and coccolithophore Emiliania huxleyi. Marine Ecology Progress Series, 147, 197-217.

[26] Oschlies, A. and Garçon, V., 1998. Eddy-induced enhancement of primary production in a model of the North Atlantic ocean. Nature, 394, 266-269

[27] Oschlies, A., 2001. Model-derived estimates of new production: New results point towards lower values. Deep-Sea Research II, 48, 2173-2197.

[28] Paasche, E., 2002. A review of the coccolithophorid Emiliania huxleyi (Prymnesiophyceae), with particular reference to growth, coccolith formation, and calcification-photosynthesis interactions. Phycologia, 40(6), 503529.

[29] Popova, E.E., 1995. Non-universal sensitivity of a robust ecosystem model of the ocean upper mixed layer. Ocean Modelling, 109, 2-5.

[30] Popova, E.E., Fasham, M.J.R., Osipov, A.V. and Ryabchenko, V.A., 
1997. Chaotic behaviour of an ocean ecosystem model under seasonal external forcing. J. Plankton Res. 19, 1495-1515.

[31] Sarmiento, J. L., Slater, R. D., Fasham, M. J. R., Ducklow, H. W., Toggweiler, J. R., Evans, G.T., 1993. A seasonal three-dimensional ecosystem model of nitrogen cycling in the North Atlantic euphotic zone. Global Biogeochemical Cycles, 7, 417-450.

[32] da Silva, A.M., Young, C.C. and Levitus, S., 1994. Atlas of Surface Marine Data. Volume 1: Algorithms and Procedures. NOAA Atlas NESDIS, 6, U.S. Department of Commerce, NOAA, NESDIS, 83.

[33] Smith, R. D., Dukowicz, J.K., Malone, R.C., 1992. Parallel ocean circulation modelling. Physica D, 60, 38-61.

[34] Tyrrell, T., Taylor, A. H., 1996. A modelling study of Emiliania huxleyi in the NE Atlantic. Journal of Marine Systems, 9, 83-112.

[35] Visbeck, M., Marshall, J.and Haine, T., 1997. Specification of eddy transfer coefficients in coarse-resolution ocean circulation models.

[36] World Ocean Database, 2001. http://www.nodc.noaa.gov/ OC5/WOD01/pr_wod01.html

[37] Yashayaev) Yashayaev, I. 2004. Annual, Seasonal and Monthly Climatology of the North Atlantic. Procedures and data set. In preparation. 


\section{Figure Captions}

Fig. 1. Diagram of NPZD model used in this study. See the appendix for definitions of the terms representing the inter-compartmental flows.

Fig. 2. Losa's et al. (2004) biological model parameters interpolated and extrapolated on the model grid.

Fig. 3. Simulated North Atlantic seasonal mean surface chlorophyll "a" concentrations, $m g \mathrm{Chlm}^{-3}$ from Experiment 1: a) Winter (Jan-Mar); b) Spring (Apr-Jun); c) Summer (Jul-Sep); d) Autumn (Oct-Dec).

Fig. 4. Simulated North Atlantic seasonal mean surface nitrate concentrations, mmolNm$m^{-3}$, from Experiment 1: a) Winter (Jan-Mar); b) Spring (Apr-Jun); c) Summer (Jul-Sep); d) Autumn (Oct-Dec).

Fig. 5. SeaWiFS seasonal mean surface chlorophyll data averaged over the period 1997-2003, mgChlm ${ }^{-3}$ : a) Winter (Jan-Mar); b) Spring (Apr-Jun); c) Summer (Jul-Sep); d) Autumn (Oct-Dec).

Fig. 6. Simulated North Atlantic seasonal mean surface chlorophyll "a" concentrations, $m g \mathrm{Chlm}^{-3}$ from Experiment 2: a) Winter (Jan-Mar); b) Spring (Apr-Jun); c) Summer (Jul-Sep); d) Autumn (Oct-Dec).

Fig. 7. Differences, in the annual mean surface clorophyll, between: Experiment 1 and Experiment 3 (a); Experiment 2 and Experiment 1 (b); Experiment 2 and Experiment 4 (c); Experiment 4 and Experiment 3 (d). The left column shows changes due to different physics for the constant (upper) and variable biological parameters (lower) cases. The right column shows the changes due to different biological formulations for the reference (upper) and test case (lower) physical formulations. See Table 2 and the text for additional details on these experiments.

Fig. 8. Differences, in the annual mean surface nitrate concentrations, between: Experiment 1 and Experiment 3 (a); Experiment 2 and Experiment 1 (b); Experiment 2 and Experiment 4 (c); Experiment 4 and Experiment 3 (d). The interpretation of the panels is the same as for Fig. 7. 


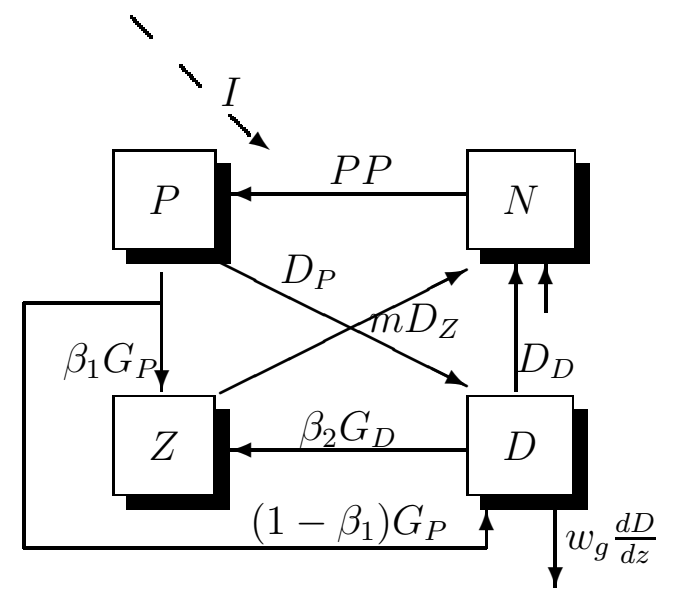

Fig. 1. 


\begin{tabular}{|c|c|c|c|}
\hline Symbol & Parameter & Values & Units \\
\hline$\mu_{1}$ & phytoplankton maximum specific mortality rate & 0.05 & $d a y^{-1}$ \\
\hline$k_{1}$ & half-saturation constant. for nutrient uptake & 0.3 & $m m o l ~ N m^{-3}$ \\
\hline$k_{5}$ & phytoplankton mortality half-saturation const. & 0.2 & $m m o l N m^{-3}$ \\
\hline$\alpha$ & initial slope of the $P-I$ curve & 0.025 & $m^{2} W^{-1} d a y^{-1}$ \\
\hline$V_{p}^{*}$ & phytoplankton maximum growth rate constant & 0.6 & $d a y^{-1}$ \\
\hline$k_{w}$ & light attenuation coefficient by water absorption & 0.04 & $m^{-1}$ \\
\hline$k_{c}$ & phytoplankton self-shading coefficient & 0.03 & $m^{2} m m o l N^{-1}$ \\
\hline$\lambda_{p}$ & $\begin{array}{l}\text { ratio of photosynthetically available radiation } \\
\text { to total irradiance }\end{array}$ & 0.41 & \\
\hline$\mu_{2}$ & zooplankton maximum loss rate & 0.25 & $d a y^{-1}$ \\
\hline$g$ & maximum specific grazing rate & 0.73 & $d a y^{-1}$ \\
\hline$k_{3}$ & half-saturation constant for grazing & 0.1 & $m m o l N m^{-3}$ \\
\hline$k_{6}$ & zooplankton loss rate half-saturation constant & 0.2 & $m m o l N m^{-3}$ \\
\hline$\beta_{1}, \beta_{2}$ & zooplankton assimilation efficiencies & 0.75 & \\
\hline$r_{1}, r_{2}$ & zooplankton feeding preferences & $0.7,0.3$ & \\
\hline$\mu_{4}$ & detrital breakdown rate & 0.05 & $d a y^{-1}$ \\
\hline$w_{g}$ & detrital sinking velocity & 10 & $m d a y^{-1}$ \\
\hline$m$ & nitrogen fraction of zooplankton losses & 0.8 & \\
\hline
\end{tabular}

Table 1

Parameters of the ecosystem model and their values in the constant parameter simulations (Popova, 1995). 


\begin{tabular}{ccc}
\hline Experiment & Biological Parameters & Version of Physics \\
\hline E1 & constant & reference \\
E2 & variable & reference \\
E3 & constant & test \\
E4 & variable & test \\
\hline
\end{tabular}

Table 2

Experiments with the coupled model. The main difference between the reference and test cases for the physics is in the specification of the surface boundary conditions for heat and salt (see text for details). 

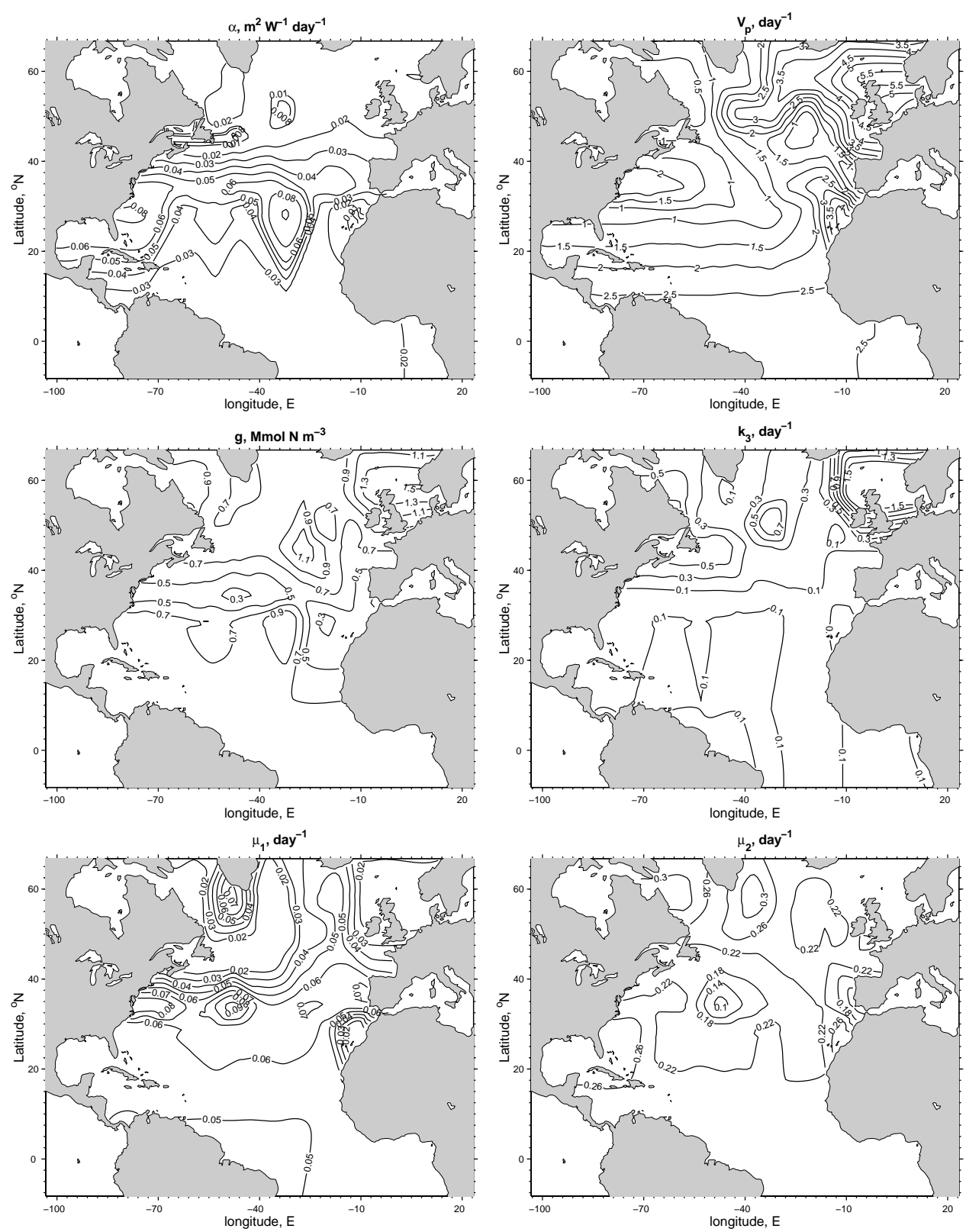

Fig. 2. 

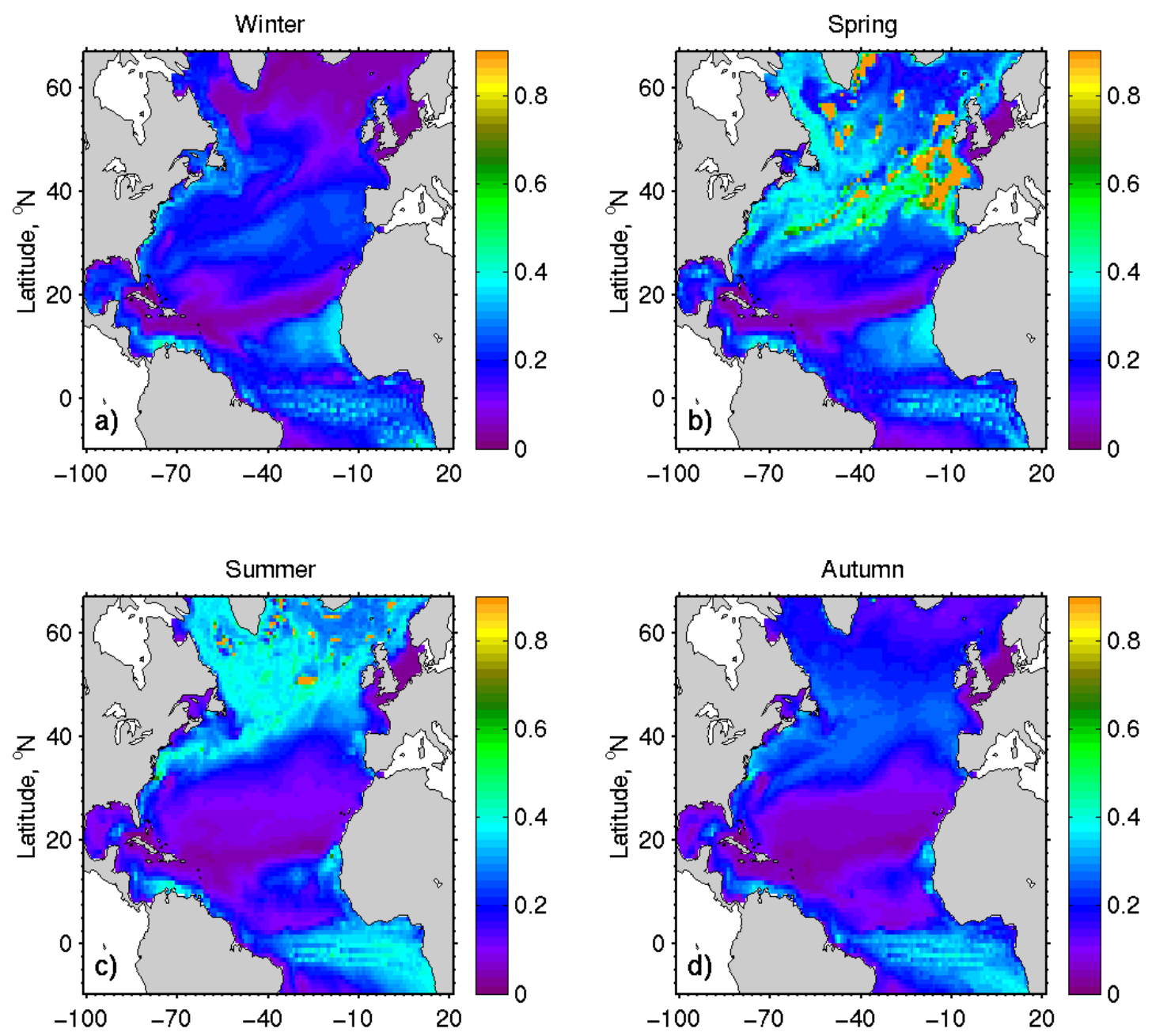

Fig. 3. 

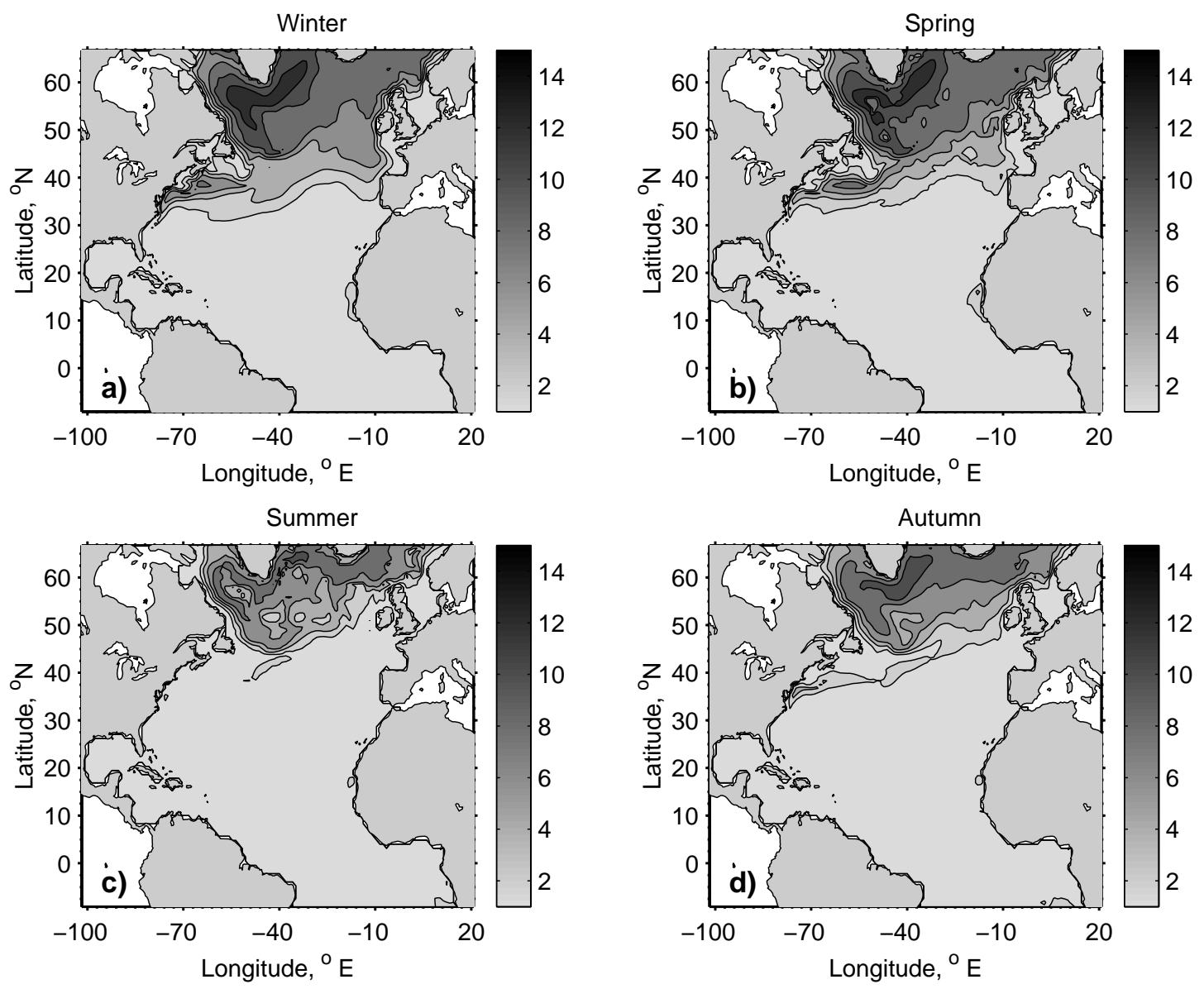

Fig. 4. 

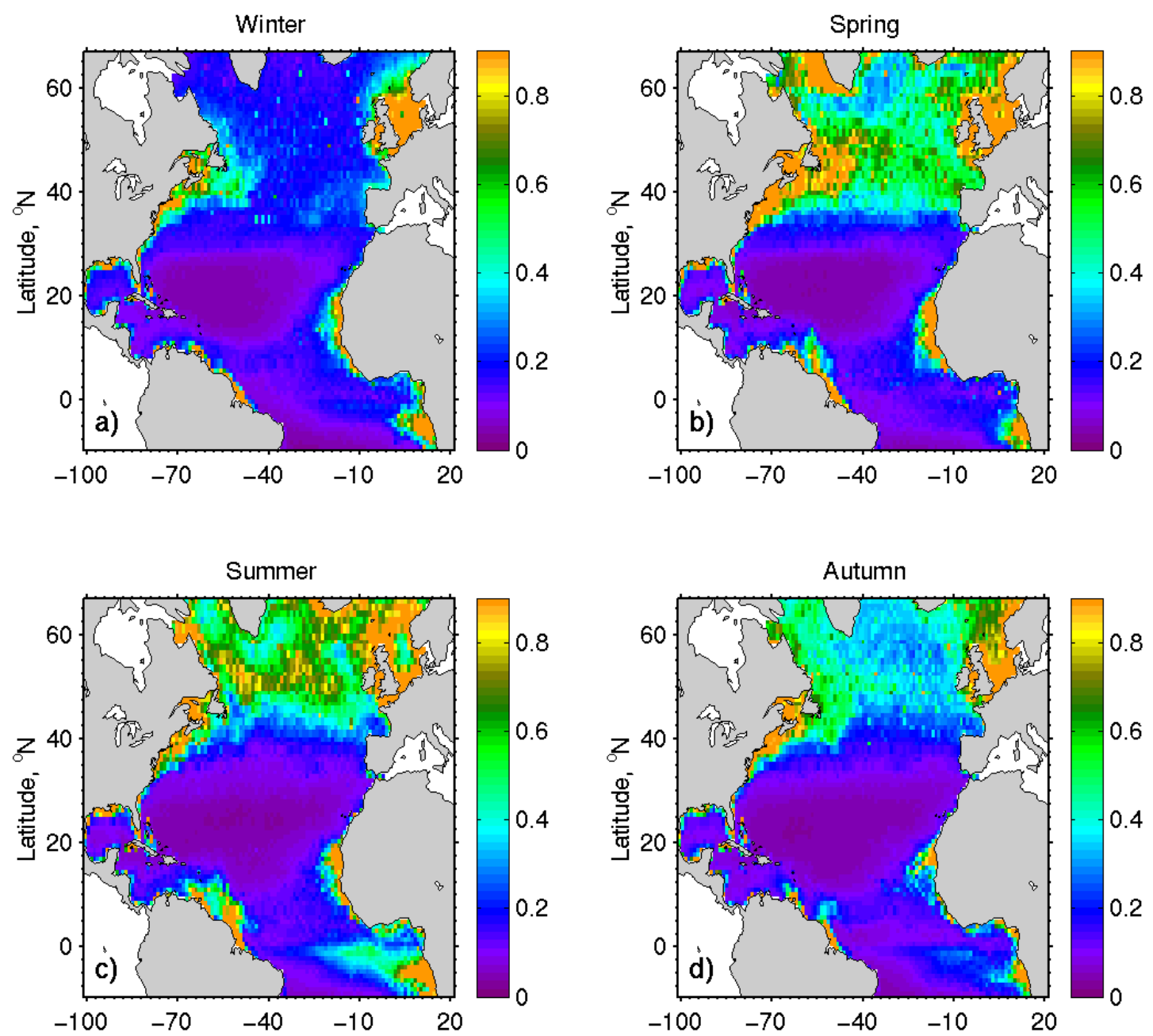

Fig. 5 . 

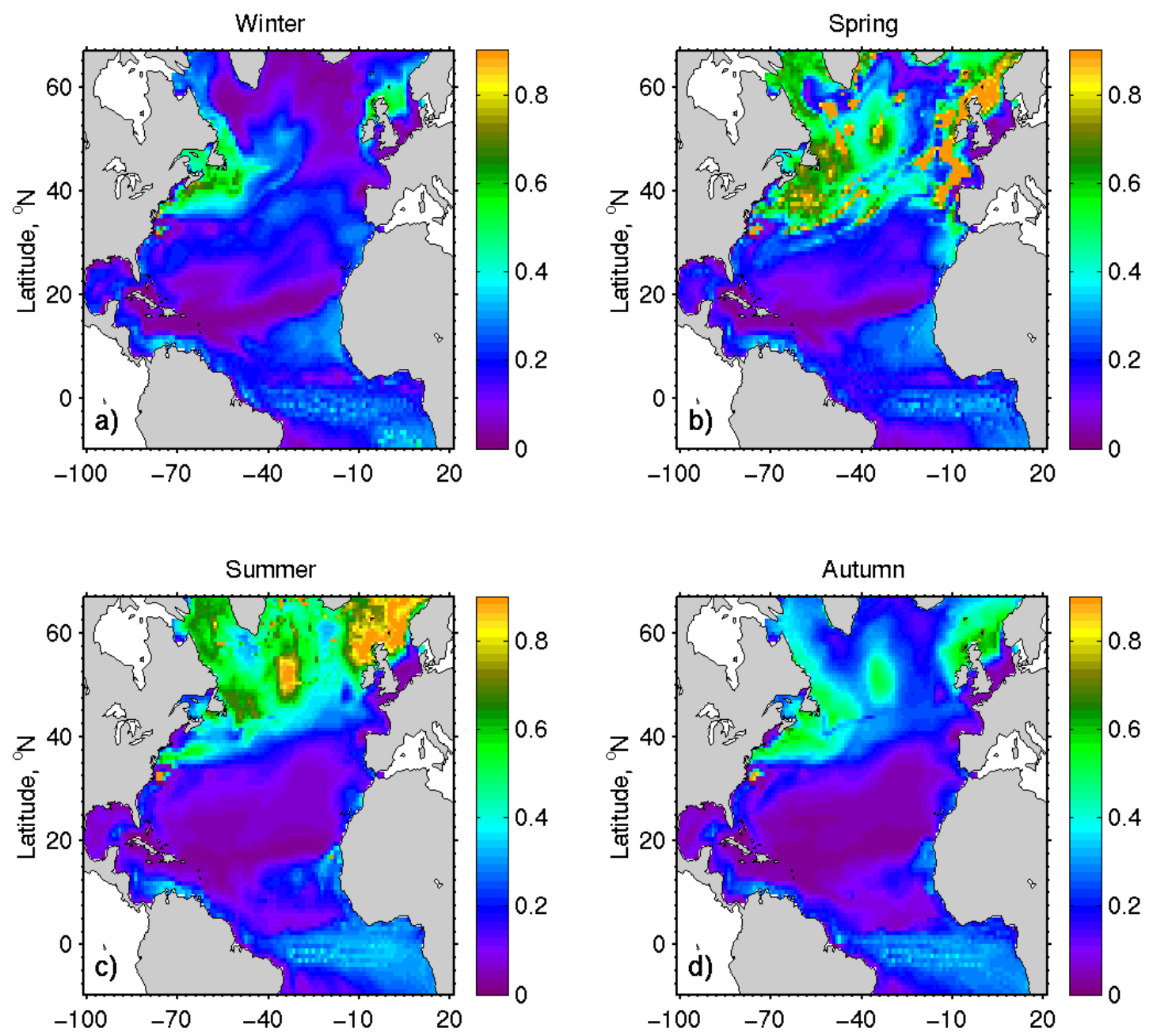

Fig. 6. 

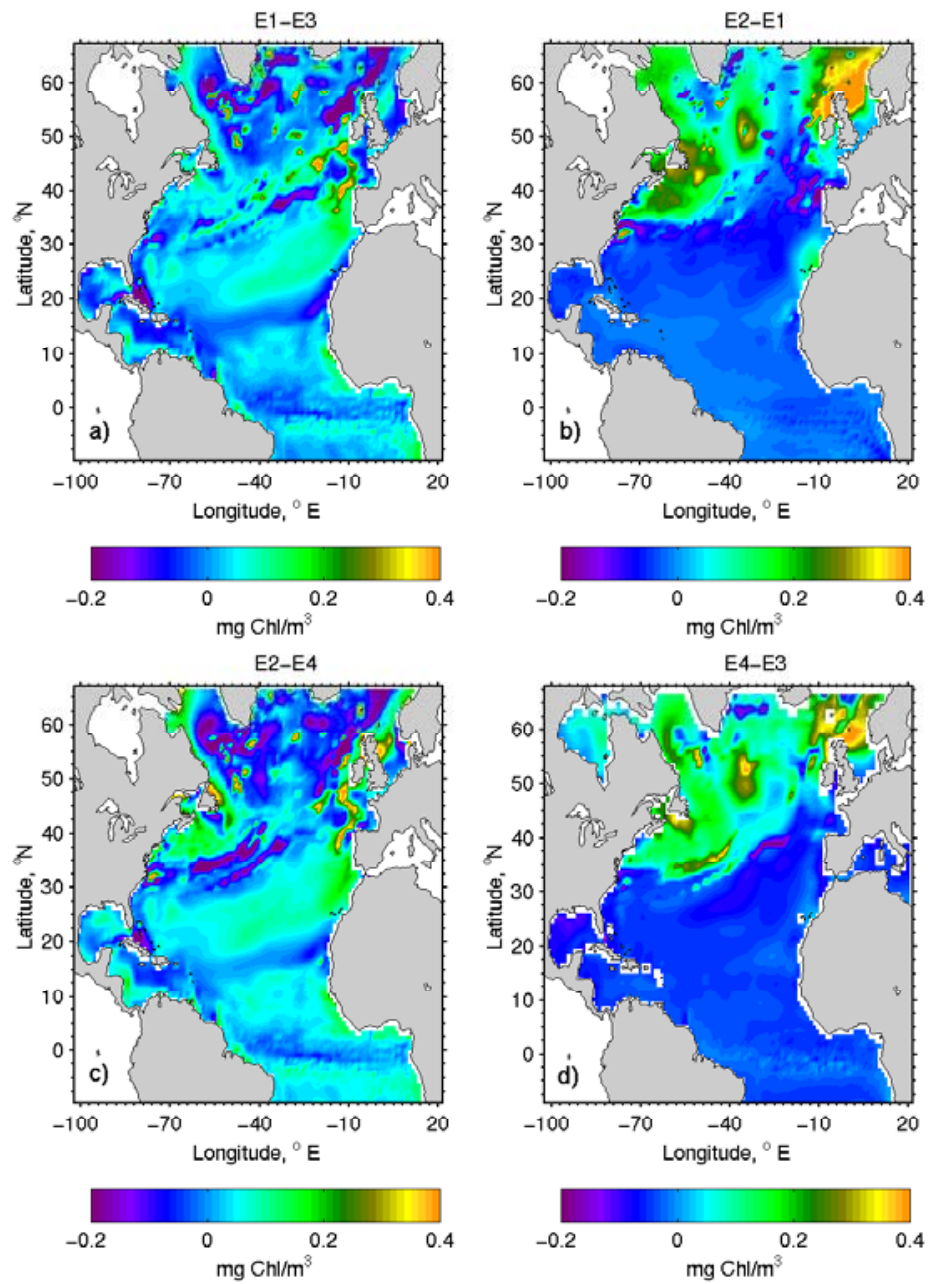

Fig. 7. 

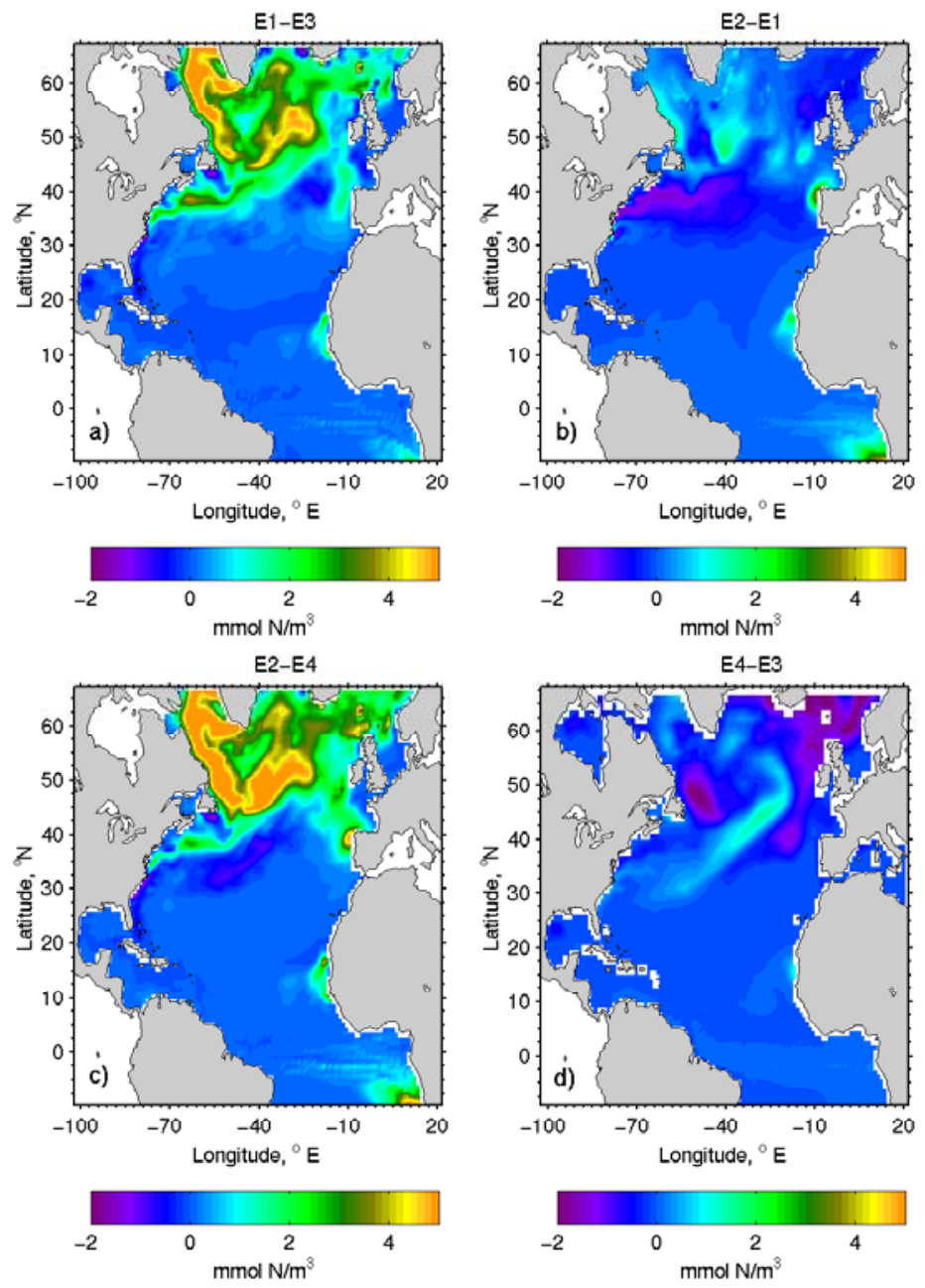

Fig. 8. 